\title{
A geophysical profile at the foot of the Dutch coastal dunes near the former outlet of the 'Old Rhine'
}

\author{
A.C. Seijmonsbergen', D.T. Biewinga ${ }^{2}$ \& A.P. Pruissers ${ }^{3}$ \\ 1 Institute for Biodiversity and Ecosystem Dynamics (IBED), section Computational \\ Bio- and Physical Geography (CBPG), University of Amsterdam, \\ Nieuwe Achtergracht 166, 1018WV Amsterdam, The Netherlands. \\ E-mail: A.C.Seijmonsbergen@science.uva.nl \\ 2 Adviesbureau voor Geofysica en Geologie, Prof. Brandsmaweg 15a, 8308RT Nagele, \\ The Netherlands. Tel: +31 (0)5276521 41, fax: +31 (0)5276521 47, \\ e-mail: d.t.biewinga@hetnet.nl (corresponding author). \\ 3 Netherlands Institute of Applied Geoscience TNO - National Geological Survey, \\ P.O. Box 80015,3508 TA Utrecht, The Netherlands.
}

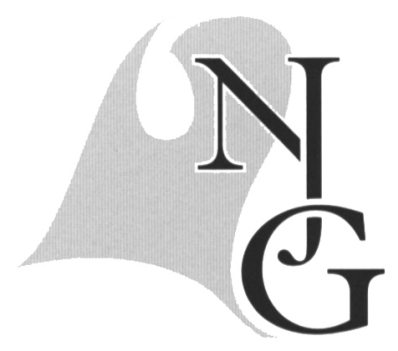

Manuscript received: April 2004; accepted: October 2004

\begin{abstract}
The apparent electrical conductivity of the subsurface along the Dutch coast between 'Wassenaarse Slag' (beach post 92.250 ) and north of Noordwijk aan Zee (beach post 77.750) reflects the spatial distribution of Holocene coastal deposits. Using a Geonics EM-34 a threefold division based on the mean electrical conductivity could be made in the outlet area of the River Old Rhine. 1) A section showing a sequence of sandy deposits that resembles the Schoorl Member of the Naaldwijk Formation on top of the Zandvoort Member of the Naaldwijk Formation. 2) A section underlain by a shallow clay/peat layer of varying thickness belonging to the Naaldwijk Formation (Walcheren Member) / Nieuwkoop Formation (Hollandveen Member), intercalated within the Schoorl Member and Zandvoort Member of the Naaldwijk Formation. South of the Old Rhine locally Wormer Member deposits of the Naaldwijk Formation underlie these clay/peat layers. 3) A section characterized by channel fill deposits of the former Rhine reaching to $-20 \mathrm{~m}$ below Normaal Amsterdam Peil (N.A.P.), and belonging to deposits of the Wormer Member of the Naaldwijk Formation, and to two facies of the Naaldwijk Formation (Walcheren Member). The geophysical transect was calibrated using existing nearby drill hole data, so that a continuous snapshot of the subsurface was gained. Therefore this research also contributes to the recent genesis of this part of the Dutch coast.
\end{abstract}

Keywords: Dutch coast, electrical conductivity, Geonics EM-34, 'Old Rhine'

\section{Introduction}

A continuous geophysical profile reflecting the mean electrical conductivity of the nearby subsurface up to approximately $15 \mathrm{~m}$ below the surface was measured between the Wassenaarse Slag (beach post $92.250 \mathrm{~km}$ ) and north of Noordwijk aan Zee (beach post 77.750 $\mathrm{km}$ ). The measurements were taken along the foot of the dunes each $20 \mathrm{~m}$ which a total profile length of $14.5 \mathrm{~km}$. Primary goal was a field test of the instrument, but to our surprise we recorded large variations in apparent electrical conductivity that correlated with lateral boundaries of the near surface coastal sediments. The electrical conductivity of a saturated material is a function of the water content and conductivity, porosity and the matrix conductivity. The latter two are related to lithology. The measured conductivity is named the apparent conductivity, because it is an average of the conductivities of the layers below the surface and not the conductivity of a single homogeneous layer. Layers deeper than the maximum depth penetration of the instrument, in this case $15 \mathrm{~m}$, have no influence on the apparent electrical conductivity. It is not the objective to elaborately describe the geological details in this article, but to emphasize the methodology. In this article we refer to the newly introduced lithostratigraphic names in the Netherlands. In the geophysical transect two formations, the 
Naaldwijk Formation and the Nieuwkoop Formation, occur. The Naaldwijk Formation has been subdivided further into the Schoorl Member, the Zandvoort Member, the Wormer Member and the Walcheren Member. Based on lithological variations in the sediments, the Walcheren Member appears in three different facies in the geophysical section. The Nieuwkoop Formation is represented in the geophysical profile by the Hollandveen Member (peat). For further details on the new lithostratigraphy is referred to De Mulder et al. (2003), Ebbing et al. (2003) and Weerts (2003).

The younger Holocene coastal deposits in the subsurface between Wassenaarse Slag and Noordwijk (Fig. 1) date back from the Late Atlantic (approximately 5,500 BP) to the present (Pruissers \& De Gans 1988). This period is known to relate to a fast relative sea level rise (Zagwijn, 1986). The following deposits can be found in the area covered by the geophysical profile: marine Wormer Member deposits, which were formed at the end of the Late Atlantic $(5,500 \mathrm{BP})$ and younger Wormer Member deposits (5,000-3,500 BP). These were formed contemporaneously with the sandy Zandvoort Member deposits of the Naaldwijk Formation. The coastline of 3,500 BP was located

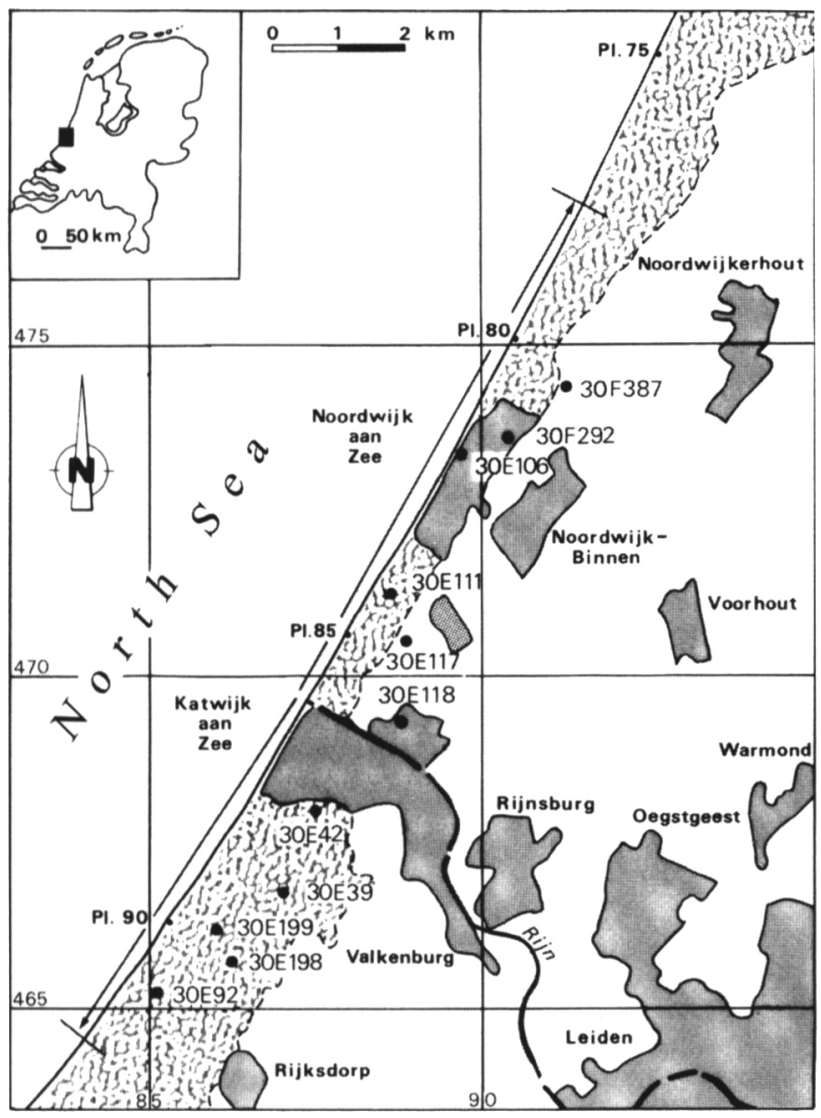

Fig. 1. Overview of the coastal area between Wassenaarse Slag and Noordwijk, showing the location of the geo-electrical profile, numbers and positions of the drill hole data used in figure 2 . The inland delineation of the dunes has also been indicated. slightly west of the present coastline. The Walcheren Member deposits of the Naaldwijk Formation are marine deposits, and reflect different facies. The Walcheren Member may exist of sandy tidal channel deposits, and tidal clay deposits. They are separated by peat, but sometimes the peat is absent. The cover and clay deposits of the Walcheren Member were formed over the Wormer Member and exist of heavy clays. The Hollandveen Member was formed over the cover and clay deposits of the Wormer Member from 2,750 BP on. Sand, alternating with clay and cover deposits of the Walcheren Member was dominantly deposited inside the tidal channels. Usually a clay layer covers the channel fills. The various channel deposits along the geo-electrical profile mainly exist of sandy Wormer Member and Walcheren Member deposits.

Both the ratio of layer thickness and depth and the contrast of the conductivity of a certain layer with the surrounding materials determine the resolution of the geophysical conductivity method. Clay and peat have a remarkable higher conductivity range than dry or fresh water saturated sandy deposits. Therefore this profile is a key section for studying lateral and vertical differences in coastal sediments.

A Dutch version of this article was originally published in 1990 in $\mathrm{H}_{2} \mathrm{O}$ (Biewinga, Pruissers \& Seijmonsbergen, 1990).

\section{Methods and measurements}

The geophysical transect was aligned to the flood line between the uppermost flood line and the foot of the dunes. The altitude is approximately $2 \mathrm{~m}$ above N.A.P. Minor height variations along the $14.5 \mathrm{~km}$ long transect occur rather smoothly, so that no sudden changes in the measured conductivity appear, due to topographical influence. Each $20 \mathrm{~m}$ a measurement was taken, the position was linked to the beach posts, which are present each $250 \mathrm{~m}$ along the Dutch coast. The apparent electrical conductivity was recorded using the induction principle with the Geonics EM 34 , oriented in the horizontal dipole mode and a coil distance of $20 \mathrm{~m}$ (Geonics Limited Technical Note $\mathrm{TN}-6,1980$ ). The depth penetration in this mode is to approximately $15 \mathrm{~m}$. The unit for the conductivity is Siemen $/ \mathrm{m}$; the instrument measures in $\mathrm{mS} / \mathrm{m}$ (milliSiemen/meter): $1 \mathrm{mS} / \mathrm{m}$ equals $1000 \mathrm{Ohm} \cdot \mathrm{m}$, $10 \mathrm{mS} / \mathrm{m}$ equals $1000 / 10=100 \mathrm{mS} / \mathrm{m}$. There is not a unique relation between (saturated) sediments and conductivity, because the conductivity is mainly determined by the salinity of the pore water, while the porosity and the material are of secondary importance. In a limited area however, it is possible to infer a certain relation between different sediments and 


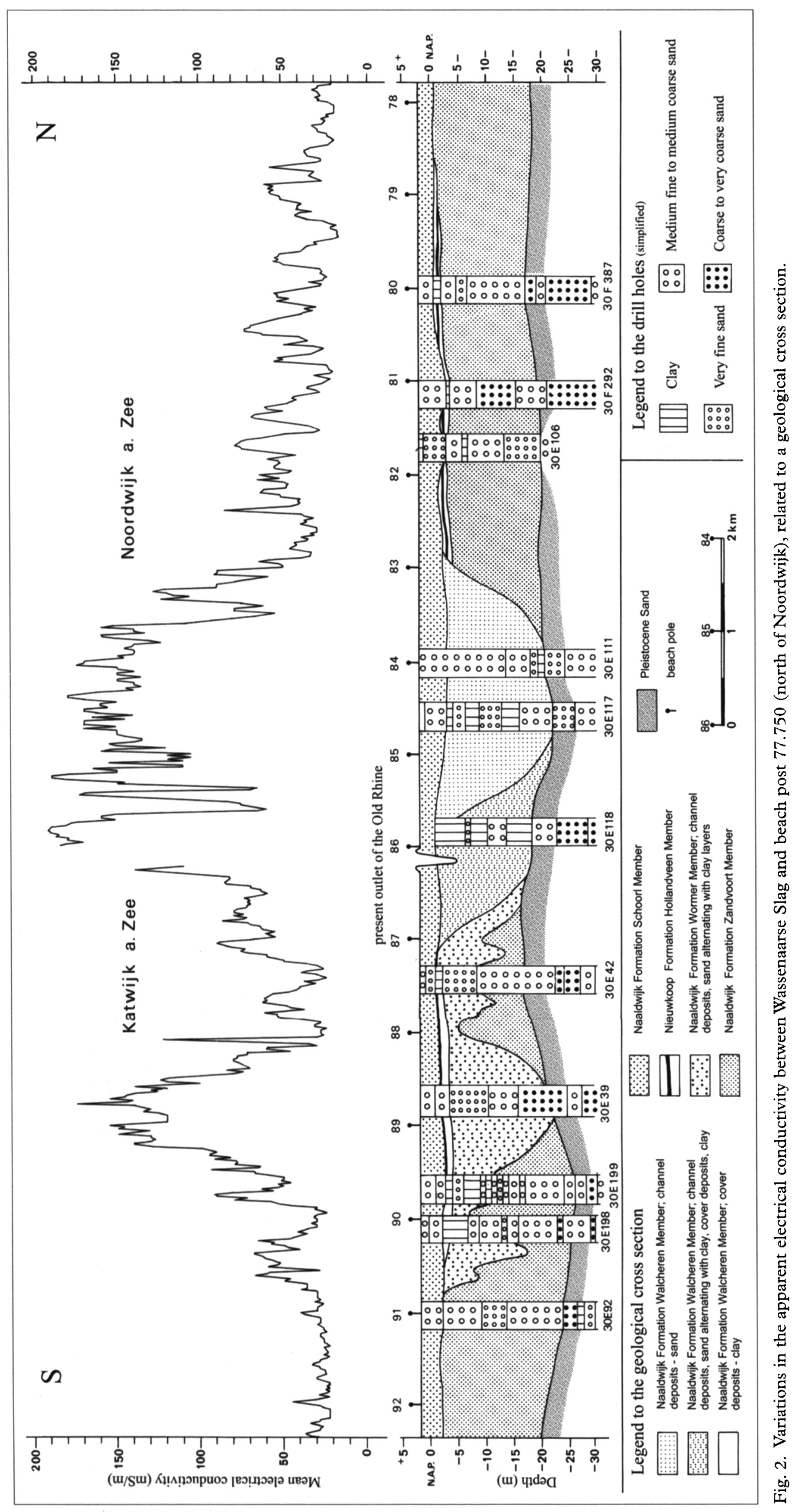

Netherlands Journal of Geosciences / Geologie en Mijnbouw 83(4) 2004 
apparent electrical conductivity. The apparent electrical conductivity is a bulk conductivity measured at the surface to which underlying sediment layers, which all have certain specific conductivities, contribute. These contributions, however, decrease with the penetration depth of the measurements. As a rule of thumb it can be stated that beyond $15 \mathrm{~m}$ the layers hardly contribute. Marine deposits in general show higher conductivity than fresh water deposits, as the result of brackish and salt water, which is commonly present in young coastal marine deposits. A clay/peat layer (saturated with fresh water) has a conductivity of about $100 \mathrm{mS} / \mathrm{m}$ (for brackish water the conductivity is higher). A sandy layer, saturated with brackish water, has a conductivity of about $20-40 \mathrm{mS} / \mathrm{m}$. A sand layer saturated with sea water has a conductivity of about $500 \mathrm{mS} / \mathrm{m}$. High apparent electrical conductivity values are reached when the conductive layer is thick and close to the surface.

\section{Results}

The apparent electrical conductivity between Katwijk and Noordwijk is presented in Fig. 2. The profile shows the relation between the apparent electrical conductivity of the subsurface and the geological interpretation based on drill hole data. The apparent electrical conductivity can be subdivided into three groups:

1. Low apparent electrical conductivities and variation in amplitude between $20-45 \mathrm{mS} / \mathrm{m}$.

2. Low to medium apparent electrical conductivities and variation in amplitude between $20-90 \mathrm{mS} / \mathrm{m}$.

3. High apparent electrical conductivity of 60-190 $\mathrm{mS} / \mathrm{m}$, which reflect saturated values and very large variation in the amplitude.

The first group, with the lowest apparent electrical conductivity values and low variation amplitudes, occurs south of beach post $90.750 \mathrm{~km}$. Sandy deposits characterize the total depth of the measurement, this relates to sandy deposits of the Schoorl Member overlying sandy deposits of the Zandvoort Member.

The second group with low to medium high apparent electrical conductivity values and large amplitude is present between beach posts $83.000 \mathrm{~km}$ and 78.500 $\mathrm{km}$. Rapid lateral and vertical changes of sediments occur within this range. The peaks in the apparent electrical conductivity relate possibly to clay/peat layers (and possibly perched water tables). The thickness could determine the height of the peak values. This is partly confirmed by the sediment sequences in boreholes 30F387, 30F292 and 30E106, which show similar variations of sequences of the clay and peat layers. Still, it must be mentioned that these drill holes are located slightly further inland (Fig. 1). The lower apparent electrical conductivities of $20-40 \mathrm{mS} / \mathrm{m}$ in this section relate to sandy deposits within the measurement range. These values are comparable with the low values we recorded in the zone south of beach post $90.750 \mathrm{~km}$. If we apply this geophysical model to the geological cross section of figure 2 , the following interpretation is made: the geological model shows a clay/peat layer at approximately $5 \mathrm{~m}$ depth (cover deposits and clay facies of the Naaldwijk Formation and Hollandveen Member of the Nieuwkoop Formation) embedded between sands of the Schoorl Member and sands of the Zandvoort Member. Differences in apparent electrical conductivity relate to differences in thickness of the layers involved. We think that these differences are the result of original depositional variations or younger removal, e.g. by erosion. At both sides of the deeper channel fill deposits between beach post $88.000 \mathrm{~km}$ and $90.000 \mathrm{~km}$, two approximately $750 \mathrm{~m}$ wide zones occur, characterized by conductivities of $20-70 \mathrm{mS} / \mathrm{m}$. Here sandy and relatively thin Wormer Member sediments underlie the shallow clay/peat layers.

The third group is related to high values and shows a large variation of the amplitudes. It is this group that reflects the channels related to the former outlet of the Old Rhine River. This high conductivity group is found roughly between Noordwijk aan Zee and Katwijk aan $Z$ Zee. We find mean values of $140 \mathrm{mS} / \mathrm{m}$ with peaks of $190 \mathrm{mS} / \mathrm{m}$. Lower values of $60 \mathrm{mS} / \mathrm{m}$ also occur in this range. Clay rich brackish channel deposits probably dominate this section of the profile, which is confirmed by drill hole 30E117 and 30E118. Between beach post $90.000 \mathrm{~km}$ and $87.750 \mathrm{~km}$ a similar, but less wide high conductivity zone occurs, probably related to a less pronounced channel. This may fit with the findings of Pruissers and De Gans (1988) and Zagwijn (1986).

The stratigraphical boundaries to $15 \mathrm{~m}$ depth in Fig. 2 are based on geophysical boundaries. Deeper boundaries are based on the interpretation of the drill hole data which are located in a few cases more than $1 \mathrm{~km}$ inland. Although in this study the influence of post depositional salinity changes in the sediments involved as the result of e.g. winter storms or sea level change has not been studied, a remarkable match of the geophysical profile and the drill hole information exists.

\section{Conclusions}

The measurements have shown that the coastal sediments at both sides of the Old River Rhine can be typified according to their apparent electrical conductivity. It was also shown that important lateral changes in sediment types and layer thickness were identified. 
A geophysical division, based on apparent electrical conductivity differences, in three groups could be made and related to existing geological drill hole information. A link to formation boundaries seems promising. A first group of low electrical conductivity was identified as sands of the Schoorl Member of the Naaldwijk Formation on top of sands belonging to the Zandvoort Member of the Naaldwijk Formation. A second group is characterized by medium to high apparent electrical conductivity. This relates to a clay/ peat layer (Naaldwijk Formation, Walcheren Member)/ Nieuwkoop Formation, Hollandveen Member) of varying thickness, north of the Old Rhine, intercalated within the Schoorl Member and the Zandvoort Member of the Naaldwijk Formation. South of the Old Rhine deposits of the Wormer Member may underlie the clay/peat layer. A third group with values up to $190 \mathrm{mS} / \mathrm{m}$ reflects clayey to fine sandy channel deposits (Walcheren Member and Wormer Member of the Naaldwijk Formation). These findings fit the present geological knowledge of the outlet area of the former Rhine. Some positions of channels may even not be known yet. Furthermore this is a quick, relatively cheap method that can also be used to locate planned drill hole sites, based on the geophysical inventory.

\section{Acknowledgements}

We would like to thank the students Physical Geography of the University of Amsterdam and Utrecht for fruitfully recording the field data. The EM-34 was kindly made available by the former Rijks Geologische Dienst in Haarlem (now TNO-NITG in Utrecht). The drill hole data used were made available to us by the former Rijks Geologische Dienst District West in Alkmaar (now TNO-NITG).

\section{References}

Biewinga, D.T., Pruissers, A.P. \& Seijmonsbergen, A.C., 1990. Het mondingsgebied van de Oude Rijn geofysisch ontsloten. $\mathrm{H}_{2} \mathrm{O}$ 11/90: 304-307.

De Mulder, E.F.J., Geluk, M.C., Ritsema, I., Westerhoff, W.E. \& Wong, T.E. (eds), 2003. De ondergrond van Nederland. Netherlands Institute of Applied Geoscience TNO - National Geological Survey. Peeters (Herent): 119-246.

Ebbing, J.H.J., Weerts, H.J.T. \& Westerhoff, W.E., 2003. Towards an integrated land-sea stratigraphy of the Netherlands. Quaternary Science Reviews 22: 1579-1587.

Pruissers, A.P. \& De Gans, W., 1988. De bodem van Leidschendam. In: Daans, F.H.C.M. \& De Kort, J.D. (eds): Over, door en om de Leytsche Dam. Geschiedenis van een gouden gemeente. Leidschendam: $16 \mathrm{pp}$.

Geonics Limited Technical Note TN-6, 1980. Electromagnetic Terrain Conductivity Measurement at low induction numbers. Geonics limited \#8, 1745 Meyerside, Dr. Mississauga, Ont., L5T 1 C6.

Weerts, H.J.T., 2003. Stratotype beschrijving van de Naaldwijk Formatie. Nomenclator Shallow Subsurface, Version 1. http://www.nitg.tno.nl/nomenclatorShallow/nl/marien/naaldwijk/ index.html

Zagwijn,W.H., 1986. Nederland in het Holoceen. Rijks Geologische Dienst. Staatsuitgeverij ('s-Gravenhage): $46 \mathrm{pp}$. 